\title{
CONTRIBUIÇÕES AGOSTINIANAS AO CONCEITO DE PESSOA HUMANA: PROBLEMAS DA IPSEIDADE E DA INTERPESSOALIDADE
}

Augustine's contributions to the concept of the human person: problems of ipseity and interpersonality

Contribuciones agustinianas al concepto de la persona humana: problemas de la pseidad y de la interpessoalidade

Mariana Paolozzi ${ }^{*}$ Universidade Federal de Santa Catarina, Florianópolis, SC, Brasil.

\begin{abstract}
Resumo
O tema da pessoa humana em Agostinho apresenta-se entrelaçado à noção de pessoa divina, de onde deriva. Buscaremos contextualizá-lo abordando alguns de seus desenvolvimentos, com ênfase nas questões da ipseidade (singularidade) e da interpessoalidade. Assim, inicialmente, será examinado o significado da pessoa humana, sob o ponto de vista da ipseidade, conforme o problema surge no I. VII do De Trinitate. Será destacada a questão dos universais e a interlocução de Agostinho com a lógica aristotélica. Em seguida, será abordada a questão da interpessoalidade; aqui, levanta-se uma oposição à tese de que há em Agostinho um certo esquecimento do "ser em relação" em detrimento da ideia de comunhão e da importância das relações interpessoais na gênese do "eu". Em suma, pretende-se apontar como a ideia de "pessoa" em Agostinho exprime, quer a individualidade (no sentido de ipseidade),
\end{abstract}

1 Universidade Federal de Santa Catarina, Florianópolis, SC, Brasil. https://orcid.org/000o0001-6729-5518. E-mail: marianapaolozzi1@gmail.com 
quer a relacionalidade. Os medievais e os contemporâneos irão trabalhar com essas noções e as desenvolverão sob o influxo do pioneirismo e do contributo agostiniano. Palavras-chave: Pessoa. Ipseidade. ilnterpessoalidade. Agostinho.

\begin{abstract}
This article focuses on Augustine's conception of the human person and shows that it derives from his notion of the divine person and expresses both individuality, in the sense of ipseity (singularity) and relationality (inter-personality). We first examine Augustine's meaning of the human person from the viewpoint of selfhood, as discussed in De Trinitate I.VII, highlighting the dialogue with the Aristotelian logic and the controversy of universals. Then, we address the issue of inter-personality by rebutting the thesis that Augustine neglects the 'being in relation' and hence the idea of communion and the importance of interpersonal relationships in the genesis of the 'self'. Medieval and contemporary philosophers will later use and develop the concepts of ipseity and relationality pioneered by Augustine.
\end{abstract}

Keywords: Person. Ipseity; Interpersonality. Augustine.

\title{
Resumen
}

El tema de la persona humana en San Agustín se presenta entrelazado en el concepto de una persona divina, de donde deriva. Trataremos de contextualizarlo abordando algunos de sus desarrollos, con énfasis en las cuestiones de la ipseidad (singularidad) y de la interpessoalidad. Así, inicialmente será examinado el significado de la persona humana, desde el punto de vista de la ipseidad, como el problema se presenta en el I. VII, del De Trinitate. Será puesto en destaque la cuestión de los universales y el diálogo de San Agustín con la lógica aristotélica. Luego, posteriormente será abordado el tema de la interpessoalidad; Aquí, se ubica una oposición a la tesis que en Agustín haya cierto olvido del 'ser en la relacionalidad' en detrimento de la idea de comunión y de la importancia de las relaciones interpersonales en la génesis del "yo". En Resumen, el objetivo es señalar cómo la noción de 'persona' en Agustín expresa tanto la comprensión de individualidad (en el sentido de la ipseidad) cuanto de la relacionalidad. Los medievales y contemporáneos trabajaran con estas nociones del tal modo que las desarrollarán bajo el influjo desde su contribución pionera y de I contributo augustiniano.

Palabras clave: Persona. Ipseidad; Interpessoalidad. Agustín. 


\section{Introdução}

O tema da pessoa humana em Agostinho apresenta-se entrelaçado à noção de pessoa divina, de onde deriva. Buscaremos contextualizar a questão da pessoa humana abordando alguns de seus desenvolvimentos, com ênfase nas questões da ipseidade (singularidade) e da interpessoalidade.

Há controvérsia quanto à existência, em Agostinho, de uma teoria do ser humano como pessoa, isto é, afirma-se que não haveria uma doutrina explícita e elaborada do ser humano como pessoa. Se, a esse respeito, não há unanimidade entre seus intérpretes, por outro lado, indubitavelmente encontramos no pensamento agostiniano uma teoria do ser humano como imagem de Deus.

Uma vez que o Deus cristão é um Deus pessoal - e visto que, no campo da antropologia, Agostinho parte de uma analogia entre Deus e o ser humano -, as implicações dessa verdade permitem uma aproximação entre duas proposições: a de que em Agostinho há uma teoria do ser humano como imagem de Deus o que, por sua vez, implicará uma compreensão do ser humano como pessoa.

Embora nem toda teoria sobre o ser humano seja uma teoria da pessoa, em Agostinho podemos dizer que ambas coincidem. Se a sua concepção do ser humano como pessoa não se apresenta plenamente desenvolvida e de forma acabada - trabalho legado à posteridade - estão lançados aí seus componentes principais: o problema da autoconsciência e seu alcance; as questões da singularidade e da interpessoalidade; o tema da liberdade e da autorrealização.

Quanto a isso, importa também notar o que ocorre com o emprego e a evolução do termo "pessoa". Em Agostinho ele é aplicado prevalentemente a Deus, e de modo infrequente ao ser humano. Se Agostinho o empregará - ao que parece de modo inédito - em referência a todo e qualquer ser humano, por outro lado não tecerá maiores considerações a respeito desse uso. Discutiremos adiante esse ponto, isto é, o modo como emprega o termo. 
Assim, o termo "pessoa" possui uma longa história. Se hoje é um importante conceito do vocabulário filosófico, antes de ingressar na filosofia e na ética transitou por vários outros campos semânticos. Saliente-se que a reflexão sobre a pessoa nos mistérios cristológico e trinitário apontou para o núcleo essencial a partir do qual foi possível pensar a similitude entre as pessoas divinas e a pessoa humana. A esse respeito vejam-se algumas interessantes passagens da obra De trinitate, onde o termo é igualmente aplicado ao ser humano:

Estas três realidades [espírito, conhecimento e amor] estão no homem, não são o homem [...]. Uma pessoa, quer dizer cada homem singular, tem em sua alma estas três coisas [...]. Porém podemos acaso dizer que a Trindade está em Deus, como uma coisa de Deus, sem ser Deus? [...]. Nada pertence à natureza de Deus que não pertença à Trindade; e as Três Pessoas são uma essência, mas não à maneira como o homem singular é uma pessoa (AUGUSTIN, 1991, p. 446, vol. 16, tradução nossa)2.

Mas na suprema Trindade, incomparavelmente superior a todas as coisas, é tão perfeita a inseparabilidade das três Pessoas, que enquanto nunca se diria que uma trindade de homens possa ser chamada de um único homem, diz-se que na Trindade divina há um só Deus. Além disso, se essa imagem que é o homem, com as suas três faculdades, é uma única pessoa, não acontece o mesmo na Trindade divina, pois aí são três as Pessoas: o Pai do Filho, o Filho do Pai e o Espírito do Pai e do Filho (AUGUSTIN, 1991, p.536, vol. 16, tradução nossa). ${ }^{3}$

2 Do original: Sed haec tria ita sunt in homine, ut non ipsa sint homo [...] Et una persona, id est singulus quisque homo, habet illa tria in mente [...] Numquid autem possumus dicere Trinitatem sic esse in Deo, ut aliquid Dei sit, nec ipsa sit Deus? [...] Nec aliquid ad naturam Dei pertinet, quod ad illam non pertineat Trinitatem: et tres personae sunt unius essentiae, non sicut singulus quisque homo uma persona.

3 Do original: Verum in illa summa Trinitate, quae incomparabiliter rebus omnibus antecellit, tanta est inseparabilitas, ut cum trinitas hominum non possit dici unus homo; in illa unus Deus et dicatur et sit, nec in uno Deo sit illa Trinitas, sed unus Deus. Nec rursus quemadmodum ista imago quod est homo habens illa tria uma persona est, ita est illa Trinitas: sed tres personae sunt, Pater Filii, et Filius Patris, et Spiritus Patris et Filii. 


\section{E também as seguintes epístolas:}

Assim como em qualquer homem (...) a alma e o corpo são uma pessoa, também em Cristo, o Verbo e o homem são uma pessoa. (AGUSTÍN, 1953, p. 523; tradução nossa) ${ }^{4}$

Do mesmo modo que na unidade de uma pessoa, a alma se une ao corpo para que o homem seja, igualmente na unidade de uma pessoa, Deus se une ao homem, para que o Cristo seja. No primeiro há mistura de alma e corpo; no último mistura de Deus e de homem. É necessário nos liberarmos de nossos hábitos perceptivos que mostram dois líquidos se misturarem ao ponto de perderem sua integridade; mesmo na ordem corporal, entretanto, a luz se mistura ao ar sem se corromper. (AGUSTíN, 1953, p. 111; tradução nossa) ${ }^{5}$

A palavra pessoa - persona - em Agostinho, quando alude a Deus é empregada para nomear as processões na Trindade, isto é as relações de origem entre Pai, Filho e Espírito Santo ${ }^{6}$.Todavia, lemos no livro V (IX, 10)) da obra De Trinitate, que o termo "pessoa" não satisfaz Agostinho. Se recorre a ele, dirá, é para não ficar em silêncio: "Tres personae non ut illud diceretur, sed ne taceretur". [AUGUSTIN, 1991, p.448, vol. 15)

Agostinho utilizou uma terminologia que já havia sido adotada anteriormente por Tertuliano, ${ }^{7}$ ao falar de Deus como uma só essência e três pessoas. Problema espinhoso: como defender a ideia de que Deus pode

\footnotetext{
4 Do original: Nam sicut in homine quolibet [...] anima et corpus una persona est, ita in Christo uerbum et homo una persona est.

5 Do original: Nam sicut in unitate personae anima utitur corpore, ut homo sit, ita in unitate personae deus utitur homine, ut Christus sit. In illa ergo persona mixtura est animae et corporis, in hac persona mixtura est dei et hominis, si tamen recedat a consuetudine corporum, qua solent duo liquores ita misceri, ut neutrum seruet integritatem suam, quamquam et in ipsis corporibus aeri lux incorrupta misceatur.

${ }^{6}$ A ideia de que o Filho provém do Pai, e de que o Espírito Santo provém de ambos, no mistério da Santíssima Trindade.

7 V. Adversus Praxeam. Ed. E. Evans. Londres: SPCK, 1948. Nessa obra encontram-se as principais reflexões de Tertualiano sobre o tema. Cf. Folch Gomes, C. A doutrina da Trindade Eterna. $O$ significado da expressão "três Pessoas". R. J.: Lumen Christi, 1979. p. 242.
} 
ser uno e trino, isto é, simples e plural sem contradição? A dificuldade estava em encontrar um termo que pudesse ser aplicado ao Pai, ao Filho e ao Espírito Santo sem, de um lado fazer deles três deuses e sem, de outro lado, dissolver a sua alteridade em uma essência única.

Tarefa inexequível? Impossível encontrar tal vocábulo, ou disparate: um Deus único e concomitantemente trino? É claro que, para Agostinho, no que se refere à natureza de Deus, a supereminência divina estava além de todos os recursos da linguagem, sendo essa, para expressá-la, sempre falha e limitada.

Mas, além dessas passagens onde se acentua a unidade da pessoa humana e sua analogia com Deus, a seguir serão apresentados e analisados excertos referentes à ideia da pessoa como ipseidade e, para finalizar, na discussão do problema da interpessoalidade será examinada a teoria da relação (conforme o I. V do De Trinitate).

\section{0 emprego da noção de pessoa humana no I. VII do De Trinitate e o problema da ipseidade}

Será examinado agora o significado da pessoa humana, sob o ponto de vista da ipseidade (singularidade), conforme o tema surge no I. VII do De Trinitate. Como a própria noção de pessoa, a questão da ipseidade não está plenamente desenvolvida em Agostinho, mas o nosso interesse é apenas em realçar o modo como o tema aí se articula, trazendo em seu bojo conteúdos que se explicitarão na posteridade, sendo por ela desenvolvidos.

Antes de avançar, resta esclarecer que, a ideia de ipseidade é entendida aqui, em sua acepção mais ampla, como aquilo que cada ser humano tem de singular, de próprio e que o distingue de todos os outros. Remete à irrepetibilidade e ao caráter particular de cada um: só existiu um Sócrates e nunca haverá outro igual, só existiu uma Hipátia e nunca haverá qualquer réplica sua, só existe um leitor como o que agora está lendo estas linhas; em suma, refere-se ao ser humano como existência singular concreta. Posto isso, avancemos. 
Visto que Agostinho julga o termo pessoa (quando empregado para se referir a Deus) arbitrário e vazio, é utilizado para não ficar sem nada dizer e aludir ao indizível: "Para falar do inefável, é necessário dizer como podemos o que não se pode explicar" (AUGUSTIN, 1991, p.526, vol. 15, tradução nossa) $)^{8}$. O hiponense não apresenta uma definição formal do termo e, acrescente-se, quando muda de registro, isto é, ao aplicar o vocábulo ao ser humano, vai usá-lo conforme um sentido que estava em circulação. É o que veremos adiante.

Considerando que Agostinho irá estabelecer um paralelo entre a pessoa divina e a pessoa humana, qual o alcance e os limites desse paralelo? Em outras palavras, qual o sentido do termo aplicado ao ser humano?

Para responder a essas perguntas, em um primeiro momento iremos averiguar o modo como o termo "pessoa" é aplicado a Deus, para depois avançar em nossos questionamentos.

O livro VII é composto de VI capítulos e os mais importantes para nosso tema são o IV, V e VI. Nesses capítulos, Agostinho discute a terminologia latina e grega da fórmula trinitária. Ele apresentará sua reserva, insatisfação e dúvidas quanto ao uso do termo "pessoa" aplicado a Deus. Nessas passagens também vai se referir ao ser humano como pessoa, de modo ligeiro e como que subrepticiamente, sem deslocar o olhar para esse tema específico; ele emprega o termo apenas na medida em que avalia os limites e alcance do vocábulo quando referido a Deus e na medida em que isso ajuda a clarificar a compreensão da natureza divina. É exatamente aí nessa "subrepticidade", nessa espécie de fenda e abertura ao nosso tema, em que iremos principalmente lançar nosso olhar. Como já dito, Agostinho considerava o termo "pessoa" impróprio para expressar a realidade divina, atribuindo as dificuldades e as contradições resultantes de seu emprego aos limites da linguagem e à inefabilidade divina. Inevitavelmente cai-se em contradição: uma vez que a essência

8 Do original: Itaque loquendi causa de ineffabilibus, ut fari aliquo modo possemus, quod effari nullo modo possumus... 
divina é única, por que não dizer que Deus é apenas uma pessoa? Ou, ao falar em três pessoas divinas, por que não considerar a Trindade como três deuses?9 Pode-se dizer que a formulação do dogma trinitário por Agostinho ficou incompleta sobre importante ponto. Não obstante, se Agostinho nunca apresentou um conceito formal do termo pessoa, por outro lado podemos analisar o modo como emprega o vocábulo, e ver algumas significativas implicações disso.

No livro VII, prosseguindo no desafio de refletir sobre a natureza divina, Agostinho: a) busca examinar quais categorias da filosofia poderiam ser aplicadas, de algum modo, ao Deus uno e trino (simples e plural); em seguida, b) investiga se e em que medida a doutrina dos universais - isto é, das ideias gerais ou predicáveis: gênero, espécie, diferença, propriedades, acidentes traz alguma luz para as relações de unidade e pluralidade em Deus. Pode-se dizer que, em última instância, nessas passagens a interlocução de Agostinho será feita - em continuidade ao livro V - com Aristóteles e sua lógica ${ }^{10}$.

a) Como compreender o que é trino em Deus e se referir a essa realidade, isto é, à simplicidade e pluralidade divina? Agostinho discorre sobre a fórmula grega para se reportar à Trindade: "uma essência, três substâncias". Cita os termos "ousia", "hipóstasis' e "prósopon" e seus modos de utilização." Discorre sobre a fórmula latina que adota, apesar de

\footnotetext{
9 A resposta a essas interrogações foi trazida séculos depois, por Tomás de Aquino (Suma, l, q 30, art. 4) e com o desenvolvimento do debate entre o nominalismo e realismo sobre a questão dos universais: não existiria uma distinção real entre pessoa e essência, mas sim uma distinção de razão. Cf. HENDRICKX, E. Introduction. In: AUGUSTIN, Saint. Oeuvres de Saint Augustin, Vol. 15: La Trinité (Livres I-VII). Paris: Institut d'Études Augustiniennes, 1991. p.48.

10 Agostinho teria tomado contato com a lógica aristotélica por meio de Plotino e da tradução de Mário Vitorino das Enéadas. Ver nota 34, p. 584, CAMELOT, Th. e MELLET, M., La Trinité. Paris: Études Augustiniennes. 1991: “D'autre part, c'est sans doute aux fragments des Analytiques insérés dans les Ennéades de Plotin, qu'il a pu lire dans la traduction de Marius Victorinus, qu'Augustin doit les éléments de logique aristotélicienne qu'il développe ici et plus loin encore, par exemple VII, 11 (Chevalier, Saint Augustin et la pensée grecque. Les relations trinitaires. Fribourg (Suisse), 1940, p. 47, n.1).

"Cf. De Trin. VII, IV, 7: "Para falar do inefável, é necessário dizer como podemos o que não se pode explicar; os gregos entre eles falam em "uma essência e três substâncias". Ao passo que os latinos empregam os termos: "uma essência ou substância e três pessoas". Como já dissemos, em nossa língua latina os termos essência e substância não possuem significado diverso." Ver
} 
empregá-la com ressalvas: "uma essência ou substância, três pessoas", acrescentando que os latinos consideram essência como sinônimo de substância'2 (AUGUSTIN, 1991, p. 538, vol. 15).

b) Após essas passagens, será retomada e desenvolvida um pouco mais a questão dos universais e a possibilidade da sua aplicabilidade ou não à Trindade. Desde o cap. 4 do I. VII vemos Agostinho tentar empregar a doutrina dos universais às relações de simplicidade e pluralidade em Deus. O conceito "pessoa", quando referido à Trindade, tem uma função: exprimir o que é três - quid tres? - em Deus. Todavia, ele serve a esse propósito? Em que medida o recurso à doutrina dos universais atestaria essa função, permitindo validar o uso do termo em sua capacidade de expressar algo da natureza divina?

Agora, os problemas e os impasses provindos do uso do termo são discutidos de modo mais explícito e sob outra luz: seria possível considerar a relação das três pessoas com a unidade de Deus, tal como uma relação de gênero com a espécie; ou da espécie com o indivíduo; ou de diversas espécies com um gênero comum superior? Não faltaram autores (da Patrística grega) ${ }^{13}$ para defender essa posição. No entanto, objeta Agostinho que em todos esses casos seria necessário pressupor três essências divinas, o que inviabilizaria a aplicação da doutrina dos universais às pessoas trinitárias.

O raciocínio aqui é basicamente o seguinte: se considero a essência um gênero, e pessoa espécie, então seria levado a dizer que na Trindade há três essências, do mesmo modo que três cavalos (espécie) não são um animal (gênero), mas três animais (possuem três essências). Ao seguirmos

também VII, VI, 11: “Os gregos, se quisessem, poderiam dizer três pessoas, três 'prósopa', assim como falam em três substâncias ou hipóstases. Preferiram, no entanto, a segunda expressão talvez por corresponder melhor à índole do seu idioma".

12 De Trin. VII. V, 10: "Fica assim claro que o termo substância em Deus não é apropriado, mas sim abusivo. Deve-se atribuir-lhe o termo mais próprio de "essência", o que se aplica verdadeira e propriamente a ele. Isso de tal modo que talvez somente Deus seja uma essência. É ele deveras o único que seja realmente, por ser imutável." O termo substância, como Agostinho explica anteriormente, designa um sujeito (subjectum) de atributos, de modo que não é próprio a Deus, apenas às criaturas.

13 Cf. HENDRICKX, E. Idem, p.36. 
essa linha de argumentação seríamos obrigados a dizer que na Trindade há três pessoas, e, portanto, três deuses (três essências). Assim, esse modelo não abarca a realidade divina.

Em meio a todo esse debate, quando Agostinho afirma a impossibilidade da aplicação da doutrina dos universais às pessoas divinas é que desponta o tema que nos interessa: a questão dos universais - mais exatamente as ideias de gênero, espécie, e também de indivíduo - associada à noção de pessoa humana. Se não é possível aplicar a doutrina dos universais ao mistério trinitário, não obstante ela se aplica à pessoa humana e ao mundo natural.

Ao refletir sobre a natureza divina, a certa altura Agostinho irá exemplificar seus argumentos com a espécie e pessoa humanas. É nesse âmbito que empregará o termo "indivíduo" (mais exatamente "individua", que é o plural de "individuum"; de acordo com o texto em latim), onde também aparece de modo claro a ideia de singularidade:

Mas se dizem que o nome de substância ou pessoa não indica uma espécie, mas algo de singular e indiviso, não se poderia empregar o nome de substância ou pessoa como se emprega o de "homem", termo comum a todos os homens. Empregar-se-ia apenas para designar um homem concreto, como Abrãao, ou Isaac ou Jacó, ou qualquer pessoa que se poderia indicar com o dedo. Com efeito, tal como denominamos Abrãao, Isaac e Jacó como três indivíduos, assim os designamos como três homens e três almas. [...] Se, porém, a essência é uma espécie, como o homem é uma espécie, as três realidades que denominamos substâncias ou pessoas, têm a mesma espécie comum, como Abrãao, Isaac e Jacó têm a mesma espécie comum, que é o ser homem. E, embora a espécie humana se partilhe em Abrãao, Isaac e Jacó, um homem não pode subdividir-se em alguns homens em particular. Não pode absolutamente, pois cada homem é um só homem. Por que então, uma essência se subdivide em três substâncias ou pessoas? Pois se a essência é uma espécie, 
como o ser homem, uma é a essência e um é o ser homem. [...] Com efeito, quando defino o homem, que é nome específico, cada um dos homens, que são indivíduos, são abrangidos pela mesma definição, e nada abrange que não seja homem (AUGUSTIN,1991, p. 542, vol.15, grifo da autora). ${ }^{14}$

Com isso, é possível considerar que, o termo pessoa significa algo mais do que "homem", mais também do que a expressão "ser humano", ele designa seres humanos determinados, "homens" determinados. Essa é a sutileza do termo: o realce da singularidade e da individualidade. Ele agrega algo mais à ideia de espécie, à ideia de homem e ser humano, isto é, deve ser concebido como um universal que ressalta a singularidade dos seres aos quais se aplica.

Os medievais darão, paulatinamente, notável desenvolvimento a esse debate. Boécio, Abelardo, Ricardo de S. Vitor, Tomás de Aquino, Duns Scotus etc. para citar alguns deles. Os desdobramentos dessa ideia, simplesmente posta e lançada aí de modo breve, em todo o seu potencial e virtualidade, serão trabalhados pelo medievo e modernidade, onde a noção de pessoa irá chegando a uns de seus campos de reflexão mais comuns hoje em dia, sua aplicação à antropologia.

Mas, para além da discussão da evolução conceitual do termo "pessoa" (o que fugiria ao nosso escopo), gostaria de salientar outro ponto para

\footnotetext{
${ }^{14}$ Do original: Quod si dicunt substantiae vel personae nomine non speciem significari, sed aliquid singulare atque individuum, ut substantia vel persona non ita dicatur sicut dicitur homo, quod commune est omnibus hominibus, sed quomodo dicitur hic homo, velut Abraham, velut Isaac, velut Jacob, vel si quis alius qui etiam digito praesens demonstrari possit: sic quoque illos eadem ratio consequetur. Sicut enim dicuntur Abraham, Isaac et Jacob tria individua, ita tres homines, et tres animae. [...] Si autem species est essentia, sicut species est homo, tres vero illae quas appellamus substantias sive personas, sic eamdem speciem communiter habent, quemadmodum Abraham, Isaac et Jacob speciem quae homo dicitur, communiter habent; non sicut subdividitur in Abraham, Isaac et Jacob, ita unus homo et in aliquos singulos homines subdividi potest: omnino enim non potest, quia unus homo jam singulus homo est. Cur ergo una essentia in tres substantias vel personas subdividitur? Nam si essentia species est sicut homo, sic est una essentia sicut unus homo. [...] Cum enim definiero quid sit homo, quod est nomem speciale, singuli quique homines qui sunt individua eadem definitione continentur, nec aliquid ad eam pertinet quod homo non sit.
} 
concluir esta seção. Podemos agora voltar a um importante elemento do pensamento agostiniano, à ideia do ser humano imago dei. Uma vez que Deus é incompreensível e inefável, e visto que somos feitos à sua imagem e semelhança, trazemos também a marca dessa incognoscibilidade: "Pois as coisas incompreensíveis devem ser buscadas de tal modo que não estime nada ter encontrado aquele que pôde encontrar quão incompreensível é aquilo que se buscava" (AUGUSTIN, 1991, p.422, vol. 16) ${ }^{15}$. Segundo Agostinho, participar da incognoscibilidade de Deus pelo ser que recebemos dele é também o que nos torna semelhantes a ele: a pessoa humana também carrega em si dose de mistério. A inefabilidade é marca (signo) não apenas do divino, mas permeia também a realidade humana e o mundo natural. Agostinho apresenta essa ideia de modo claro, quando, por exemplo, discorre sobre a morte e o significado do tempo.

[...] Mas quando a alma se separar, retirando ao corpo toda a sensibilidade, o homem estará "depois da morte" e dir-se-á que está morto. Perece, pois, entre o momento em que está a morrer e o momento de "estar na morte"- porque, se vive ainda, está "antes da morte"; se deixou de viver, está já "depois da morte"; nunca, portanto, se está a morrer, isto é, "na morte". Da mesma forma, no decorrer do tempo procura-se o presente sem que seja possível encontrá-lo, porque a passagem do futuro ao passado é sem duração. Não parece que, depois deste raciocínio, se tem de negar a morte corporal? Se há morte - onde é que ela está que em ninguém pode ela estar e ninguém nela pode estar? Se se vive - ela ainda lá não está; se se está antes da morte, não se está na morte; se se deixou de viver - já lá não está porque se está "depois da morte". Mas se não há morte nem "antes" nem "depois", a que propósito dizer "antes da morte" e "depois da morte"? Se não há morte, tudo o que se está a dizer é falho

15 Do original: Sic enim sunt incomprehensibilia requirenda ne se existimet nihil inuenisse qui quam sit incomprehensibile quod quaerebat potuerit inuenire. 
de sentido. Oxalá tivéssemos vivido bem no Paraíso para que morte não houvesse realmente! Mas no presente não somente existe mas é ela tão penosa que ninguém a pode explicar com palavras nem com raciocínio algum se pode evitar! (AGOSTINHO, 2000, p.1179-1180) ${ }^{16}$

Explicar a morte a partir da própria experiência é impossível; deter o tempo é impossível (o presente tende a não ser e é inapreensível de modo permanente); o ser humano também traz inscrito nele o que o supera.

Em suma, se a pessoa divina não pode ser entendida a partir das categorias gênero, espécie, indivíduo, no entanto com a realidade humana acontece algo diverso. A ideia de pessoa - e isso não há em Aristóteles - foi associada à de indivíduo, espécie humana e gênero animal. Se já se trabalhava com os conceitos de gênero, espécie e indivíduo, adiciona-se outros elementos a essas fórmulas, trazendo-Ihes maior agudeza e precisão-a própria ideia de ipseidade que começava a ser explicitada e conceituada; isto é, uma compreensão mais aguda do humano, realçando-se nela mesma, a boa convivência e a familiaridade com o âmbito do mistério, e da inefabilidade.

\section{A questão da interpessoalidade}

Geralmente considera-se que, dentre as filosofias contemporâneas da pessoa, seja um traço distintivo do século XX a ênfase na importância

\footnotetext{
16 Do original: [...] Cum vero anima abscesserit omnemque abstulerit corporis sensum, iam post mortem mortuusque perhibetur. Perit igitur inter utrumque, quo moriens vel in morte sit; quoniam si adhuc vivit, ante mortem est; si vivere destitit, iam post mortem est. Numquam ergo moriens, id est in morte, esse comprehenditur. Ita etiam in transcursu temporum quaeritur praesens, nec invenitur, quia sine ullo spatio est, per quod transitur ex futuro in praeteritum. Nonne ergo videndum est, ne ista ratione mors corporis nulla esse dicatur? Si enim est, quando est, quae in ullo et in qua ullus esse non potest? Quando quidem si vivitur, adhuc non est, quia hoc ante mortem, non in morte; si autem vivere iam cessatum est, iam non est, quia et hoc post mortem est, non in morte. Sed rursus si nulla mors est ante quid vel post, quid est quod dicitur ante mortem sive post mortem? Nam et hoc inaniter dicitur, si mors nulla est. Atque utinam in paradiso bene vivendo egissemus, ut re vera nulla mors esset. Nunc autem non solum est, verum etiam tam molesta est, ut nec ulla explicari locutione possit nec ulla ratione vitari".
} 
da interpessoalidade na constituição do eu. Segundo essa perspectiva, a antropologia agostiniana e aquela da Idade Média, caracterizam-se por um certo esquecimento do "ser em relação" em detrimento da ideia de comunhão e da importância das relações interpessoais na gênese do "eu"17.

A nosso ver, no que concerne ao pensamento agostiniano, essa análise não é justa. Para combater a heresia ariana, Agostinho refletiu sobre a unidade das pessoas divinas, o que o levou à elaboração e transformação do conceito substancial de pessoa divina em um conceito relacional. Para isso recorrerá à teoria aristotélica das relações (doutrina das categorias). Agostinho lida claramente com a ideia de relação entre as pessoas divinas e a transpõe para o plano do ser humano. Mas em que medida a desenvolve, e como a aplica às relações humanas?

Ele elabora uma visão do ser humano como algo que se forma e se desenvolve a partir de suas relações consigo próprio, com os outros e com Deus. Quando examina as relações divinas (entre Pai, Filho e Espírito Santo) e a analogia com o ser humano, sua investigação se voltará em direção a uma reflexão sobre as relações exteriores do ser humano (relações interpessoais) a partir da importância do amor e do conhecimento. Isto é, apresentará uma análise minuciosa a respeito do papel do amor e do conhecimento na interioridade, que a seu turno envolvem relação com a exterioridade e o outro. Assim, a importância da interpessoalidade em Agostinho pode ser apreendida mediante esses dois atos fundamentais do ser humano, levando-se em conta o aspecto social da epistemologia agostiniana e o aspecto relacional do amor.

Acompanhemos agora alguns pontos da recensão histórica apresentada por Paul Mcpartlan (2004, p. 1395) concernente à "saída de si" e ao "ser em relação", à qual opomos uma crítica no que toca a interpretação do pensamento agostiniano, mas que não obstante proporciona uma visão abrangente sobre o assunto.

17 Pessoa (verbete). In: MCPARTLAN, Paul. Dicionário Crítico de Teologia. São Paulo: Loyola, 2004, p. 1395-1396. 


\section{1 "A saída de si"}

Conforme Paul Mcpartlan, a patrística grega teria se encaminhado para uma definição das pessoas divinas, quanto do ser humano, como ser em comunhão, ao passo que a tradição latina teria acentuado, neste último, a unicidade insubstituível e a individualidade, deixando a ideia de interpessoalidade e de comunhão em segundo plano e mesmo até levando-a um desaparecimento puro e simples.

Seguindo essa linha de pensamento, Agostinho teria cometido um erro decisivo ao não buscar um análogo das pessoas divinas nas relações entre os seres humanos e ao apresentar uma tríade de processos mentais - memória, inteligência e vontade - como a imagem da Trindade no ser humano. Desse modo, o hiponense não teria fornecido «nenhum apoio à ideia de uma personalidade humana fecundada por relações interpessoais» (MCPARTLAN, 2004, p. 1396). Boécio (2005, p. 165), por sua vez, teria aprofundado essa tendência com sua célebre definição de pessoa: "substância individual de natureza racional" (naturae rationalis individua substantia).

$\mathrm{Na}$ definição boeciana a pessoa possui uma existência substancial, existe em si e como que para si. Para alguns intérpretes, tal definição não pode ser empregada na teologia trinitária - por não abarcar a interrelação, o ser-para (esse ad) -, como também na cristologia, uma vez que não permite pensar o ser-num-outro (próprio à natureza divina de Cristo). Assim, a definição de Boécio acabaria permanecendo no campo da antropologia ${ }^{18}$ eliminando o status da relação.

Segundo essa interpretação, em Agostinho e Boécio observa-se um apagamento da ideia de interpessoalidade (ou podemos dizer, de relação). Nessa trilha, a modernidade teria seguido a via do esquecimento do "ser em relação", característico da antropologia medieval, enfatizando a ideia de individualidade ensimesmada e autônoma; tal como vemos em

18 Cf. MCPARTLAN, 2004, p. 1396. Note-se que Tomás de Aquino defenderá a ideia de que a definição de Boécio se aplica também às pessoas divinas. 
Descartes, por exemplo, onde a subjetividade é considerada o essencial da pessoa. Locke e seus contemporâneos também não teriam atribuído, na constituição do eu, o mínimo papel à interpessoalidade. $O$ eu descrito por esses autores refere-se basicamente à difundida ideia de que a humanidade se compõe de indivíduos fundamentalmente independentes e autônomos, ponto de vista que o liberalismo do séc. XVIII também adotará. Passando do ego cartesiano ao eu kantiano, depois ao idealismo alemão e, para além dele, pressupõe-se então "um entendimento tácito sobre a possessão de si por si” (MCPARTLAN, 2004, p. 1397).

Dentro desse quadro, Mcpartlan (2004) acrescenta que Hegel (séc. XIX) será considerado um filósofo da "saída de si" e, note-se, quanto tempo transcorrido desde Agostinho... Dirá, no entanto, que se em Hegel as relações aparecem na gênese da pessoa, o fim desta implica um retorno a si e um satisfazer-se consigo. Adiante apresentará Marx como o primeiro a elaborar uma crítica sistemática à subjetividade, fazendo da pessoa o produto de relações. E concluirá a seção apresentando algumas reflexões sobre o aparecimento, no séc. XX, das filosofias às quais se pode atribuir papel relevante à ideia de comunhão na gênese do eu.

Realçará em seção posterior ${ }^{19}$ que a definição de Locke de pessoa, ainda que tenha cedido lugar a outras concepções na filosofia, continuaria difundida na mentalidade geral: a de pessoa concebida como célula autônoma. As considerações finais de McPartlan se dirigirão principalmente a apresentação de teorias contemporâneas, da teologia à ontologia, que agregam, de diversas maneiras, a ideia de interpessoalidade, recusando por exemplo, uma concepção monádica de si e abarcando a ideia de comunhão.

Após esses breves comentários sobre a "saída de si" e o "ser em relação", procura-se a seguir examinar alguns elementos do pensamento agostiniano sobre a interpessoalidade, contrapondo-se, assim, à visão de McPartlan a respeito do tema.

19 Ver MCPARTLAN (2004, p. 1397): C) Da teologia à ontologia. 


\subsection{Reflexões sobre a teoria da relação (De Trinitate I. V)}

a) Pessoa divina - Conforme referido anteriormente, o ponto de partida para a elaboração da antropologia agostiniana será o das pessoas divinas: o nexo entre as pessoas divinas e a pessoa humana será investigado por Agostinho e configurará uma série de consequências ${ }^{20}$ significativas. A base da antropologia agostiniana é clara: tendo o ser humano sido criado à imagem e semelhança de Deus é possível estabelecer uma analogia entre ambos. 0 Deus cristão - pessoal e trino-, é por assim dizer, um Deus societário ${ }^{21}$. Uma vez que a Trindade não é "solidão do uno", tem-se nela a base metafísica e o modelo a todo tipo de sociabilidade e à ideia de interpessoalidade.

Novamente, como Agostinho compreenderá e desenvolverá esses temas? Debate controvertido; no entanto, a nosso ver ao examinar o sentido da noção de relação em Agostinho a resposta ao questionamento levantado ficará mais clara.

As principais discussões agostinianas referentes à ideia de pessoa e de relação encontram-se no já citado livro $V$ do $D e$ Trinitate. De modo muito significativo o conceito de pessoa divina será transformado em um conceito relacional e, para realizar essa operação, Agostinho recorre à teoria aristotélica das relações (seu intuito principal era refutar o arianismo ${ }^{22}$ ).

De acordo com Aristóteles (2005) as coisas pertencem ou à categoria de substância ou a uma das categorias dos nove acidentes. ${ }^{23}$ Assim, a partir do aristotelismo os arianos vão sustentar que as distinções relativas à natureza divina deveriam ser predicadas substancial ou acidentalmente. Porém, uma vez que acidentes implicam a possibilidade de mudança, e Deus é imutável, a distinção entre o Pai e o Filho deve ser dita e pensada

\footnotetext{
20 Se formos pensar, por exemplo, em termos éticos, é preciso citar a própria ideia de livre-arbítrio e liberdade discutidas por Agostinho.

21 E isso o distinguirá dos outros dois monoteísmos.

22 Arianismo: heresia dos primeiros tempos da Igreja primitiva, baseada em visão cristológica sustentada pelos seguidores de Ário, na qual se negava a consubstancialidade entre Jesus e Deus Pai.

${ }_{23}$ Ver Órganon. Categorias, 4, 2005, p. 41-49.
} 
de acordo com a substância. Mas isso levaria - em contradição com a ortodoxia - à conclusão de que o Pai e o Filho possuem diferentes substâncias.

A refutação agostiniana dessa posição implicará no emprego da quarta categoria aristotélica: a das relações. Todavia, e isto é importante, seu sentido acabará sendo modificado por Agostinho. Vejamos a posição agostiniana. Inicialmente, baseando-se no pensamento aristotélico, admite-se que tudo o que é dito das coisas criadas refere-se à substância ou aos acidentes ${ }^{24}$ ). Entretanto, não acontece o mesmo quando se fala sobre Deus: nada se refere a acidentes ou qualidades, uma vez que ele é substancialmente simples. E aqui entrará o argumento agostiniano capital: há certas coisas a respeito de Deus que, para serem expressas, não são ditas nem substancial ou acidentalmente, mas de acordo com a ideia de relação.

De Aristóteles, Agostinho retira a análise das relações recíprocas e mútuas, como a do amigo para amigo, a do pai para filho. Irá desenvolvê-la transformando-a completamente. Isto é, aqui teríamos como que a antecipação daquilo que posteriormente, na escolástica, será chamado de "os transcendentes"25. Na escolástica esse é um termo utilizado para designar categorias mais gerais do que as categorias aristotélicas. A relação em Agostinho seria como um "transcendente", algo predicado de todo ser, e para além das categorias aristotélicas. Desse modo, atribui-se lhe um novo status, retirando-a das categorias aristotélicas. Isso é absolutamente importante, uma vez que garantirá à interpessoalidade, por meio da ideia de relação, um lugar ineliminável (tal como a ideia do Deus societário). É a partir desse embasamento que será possível então, o desenvolvimento de uma metafísica do amor e uma epistemologia que sempre rementem à ideia de relação e interação.

b) Pessoa humana - Agora a pergunta que se interpõe é: se Agostinho transformou o conceito de pessoa divina em um conceito relacional, e

\footnotetext{
24 Ibid., V, p. 6

${ }_{25}$ Ver o artigo de PAIVA, G. B. V. Transcendentes ou transcendentais? Um ensaio sobre Kant e o erro dos escolásticos. Cadernos de Filosofia Alemã; v. 20; n. 2, p. 179-200, 2015..
} 
aqui estão de acordo seus intérpretes, teria feito a mesma transposição para o de pessoa humana?

Para A. C. Lloyd ${ }^{26}$, em De trinitate a metafísica agostiniana da imagem deveria no mínimo ter aberto a possibilidade de modelar as relações exteriores entre os seres humanos a partir das relações interiores das pessoas da Trindade, o que em seu ponto de vista não ocorreu.

No entanto, O'Connor ${ }^{27}$ contesta Lloyd e discorre sobre a metafísica do amor e a epistemologia agostiniana a fim de mostrar como tema da interpessoalidade está presente em Agostinho. Nesse sentido, haveria no De Trinitate uma teoria do ser humano como imagem de Deus que se aproxima de uma visão relacional da pessoa. Se não há em Agostinho uma ruptura com a teoria do eu como substância, ele avançará consideravelmente para além dos limites dessa teoria aproximando-se de uma visão relacional.

\section{Considerações finais}

Vimos em Agostinho, ao menos foi o que se pretendeu enfatizar, que a ideia de "pessoa" exprime, quer a individualidade (no sentido de ipsei-

${ }^{26}$ LLOYD, A. C. On Augustine's Concept of a Person. In: Augustine: A Collection of Critical Essays, R. A. Markus, ed. Garden City, NY: Doubleday, Anchor, 1972. p. 204: "Anyway, he did not accept the opportunity of making an analogy between the interior relationships of the Trinity and exterior or mutual relationships of humans persons."

27 O' CONNOR, W. R. O. The Concept of the Person in St. Augustine's De Trinitate. Augustinian Studies, Vol. 13, 1982, pp. 133-143. A respeito da metafísica do amor, lemos na p. 139: “In Book $V$ Augustine states that the Holy Spirit is the principle of unity within the Trinity $(V$, 12). Furthermore, the Holy Spirit is also our Spirit, since he has been given to us ( $V, 15)$. The role of the Holy Spirit as the principle of unity both within the Trinity and among those who follow God is stressed by Augustine. He explicitly states that we are to imitate the unity of the Trinity both in relation to God and among ourselves. Here we find Augustine drawing the very analogy between the interior relationships of the Trinity and the exterior relationships of human beings that Lloyd claims he never makes...." Ver De Trinitate I. VI, 7. Sobre a questão da epistemologia agostiniana comenta O'Connor (p. 142): "His theory of knowledge, however, also takes him in the same direction, i.e., towards a more relational view of the human being. For there is a decidely social cast to Augustine's epistemology. This expresses itself in the theory of divine illumination present in De Trintitate, according to which human knowledge involves a special activity of God." 
dade), quer a relacionalidade. Em outras palavras, o ser humano é "um ser em (si) e para a relação". Os medievais irão trabalhar com essas noções e as desenvolverão. É interessante notar que, conforme salienta José M. S. Rosa, ${ }^{28}$ quando Boaventura se refere à personna como relação, ele vê aí "o ápice, ou a suma expressão, de uma relacionalidade" (ROSA, 2008, p. 286) que começa na corporeidade. A alma, por sua vez, é compreendida como instância "radicalmente comunicativa e relacional" (ROSA, 2008, p. 286):

De novo, o homem surge como um nó ou feixe de possibilidades: já nas cinco portas do corpo, isto é, pelos cinco sentidos, o ser humano apresenta uma dimensão essencialmente relacional e de abertura a todo o universo [...] O homem todo é radicalmente um ser em aberto, desde a sua inscrição corpórea no cosmos até ao gume do espírito (acies mentis): é esse in e, simultaneamente, esse ad, 'ser em si' e 'ser para outrem', ontológica intencionalidade. (ROSA, 2008, p. 285-286)

Todavia, se não há em Agostinho definição de "pessoa", não ocorre o mesmo com seus sucessores, sob o influxo do pioneirismo e contributo agostiniano. Cabe recordar a importante passagem da obra Ordinatio, ${ }^{29}$ onde Duns Scotus menciona duas definições desta noção que se tornaram clássicas:

Aceito a definição [de pessoa] que dá Ricardo de S. Vitor [De Trinitate 4, 22], a saber, que 'a pessoa é a existência incomunicável de natureza intelectual', cuja definição expõe e corrige a definição de Boécio, que afirma: 'a pessoa é uma substância individual de natureza racional' (...), [e corrige-a] porque esta definição implicaria que a alma fosse pessoa, o que é falso (apud ROSA, 2008, p. 287).

\footnotetext{
${ }_{28}$ João Duns Scotus (1308-2008). Homenagem de scotistas lusófonos, org. Luis Alberto De Boni. Porto Alegre: EST-EDIPUCRS-Universidade São Francisco, 2008. p. 286.

29 Apud Rosa, J. M. S., idem, p. 287: Ord. I, d. 23, n. 15.
} 
A essas duas definições acrescente-se a fórmula de Duns Scotus: "persona est ultima solitudo" (a pessoa é solidão derradeira)..$^{30}$ À evolução da noção de pessoa será agregado o matiz da ideia de incomunicabilidade, que Scotus teria retirado da defnição de Ricardo de São Vitor. O primado ontológico do singular, expresso aqui pela incomunicabilidade, e que pode, por exemplo, ser reconhecido na expressão haecceitas ("este ser aqui"; ecceidade, ou ipseidade), ganhará designação clara. A pessoa é ímpar, singular, rigorosamente 'fora de série', ou se quisermos, vive em contínuo "estado de exceção". ${ }^{31} \mathrm{~A}$ isso Duns Scotus chama incommunicabilitas ut quod, e é neste sentido que se emprega a enigmática expressão: ultima solitudo; a pessoa como solidão última. $\mathrm{E}$, consequência significativa, por ser ultima solitudo, é que a pessoa pode experimentar a si mesma como mistério insondável de liberdade.

No processo da construção de si (individual e coletivo) - onde o ser humano é concebido como unidade in fieri - ${ }^{32}$, a invenção da "pessoa" seria do porte da invenção da linguagem, por exemplo, para podermos dimensionar a relevância do tema. E ressaltando a antiguidade desse longo processo histórico, diz Vaz:

Antes, no entanto, de começar a se delinear e a se definir com nitidez na cultura grega e na cultura hebraica, das quais procede a nossa, a experiência do existir pessoal foi precedida pelo multimilenar processo de emergência do indivíduo desde o seio dos dois grandes abrigos simbólicos que o protegeram durante a longa noite da pré-história e durante as primeiras e ainda indecisas luzes do dia da história: a Natureza e a Sociedade ${ }^{33}$.

\footnotetext{
30 Apud Rosa, J. M. S, idem, p. 281. Ver Ord. III, d. 1, q. 1, n. 68.

31 Idem, p. 281.

32 Ver Vaz, H. C. L., Antropologia Filosófica II. São Paulo: Loyola, 1992, p. 144.

33 Idem, p. 200-201.
} 
A esse respeito, reportamo-nos a Teilhard de Chardin ${ }^{34}$, para quem todas as leis do cosmos, toda a evolução - compreendida como o desenvolvimento de uma complexidade crescente - parece conduzir à interioridade máxima (da consciência), sinalizada pela pessoa humana. Para ele, no momento em que aparece o ser humano, o processo de interiorização e de reflexão se aprofunda: a interiorização de si mesmo pode ser tida como individualização máxima. Assim, o que caracteriza a pessoa é seu poder reflexivo e a consciência.

Teilhard de Chardin busca descrever aquilo que considera como o processo de personalização do ser humano e do Universo. Concordando ou não com suas reflexões (e a despeito de em seu pensamento haver a confluência entre filosofia, ciência e teologia) é interessante recordar sua tentativa de sintetizar, no séc. $X X$, as ideias de ipseidade e interpessoalidade, postas por Agostinho, remotamente nos séculos IV-V. Nesse sentido, fica então a interrogação a respeito do alcance da descoberta da pessoa e da sua invenção. Parece que ainda estamos tateando.

\section{Referências}

Fontes primárias (edições e traduções):

AGOSTINHO (Santo). A cidade de Deus. Tradução de J. Dias Ferreira. Lisboa: Calouste Gulbenkian, 2000. v. II, livro IX a XV.

AGOSTINHO (Santo). A trindade. Tradução de Agustino Belmonte. São Paulo: Paulus, 1995.

AGUSTíN (San). Cartas (20): 124-187. Tradução de L. Cilleruelo. Madrid: Biblioteca de Autores Cristianos, 1953. Edição bilíngue latim-espanhol. Obras completas de San Agustín.

AUGUSTIN (Saint). Oeuvres de Saint Augustin. Traduc,ão e notas de M. Mellet e T. Camelot. Paris: Institut d'Études Augustiniennes, 1991. (La Trinité, v. 15, livres I-VII).

34 Ver: Chardin, T. O Fenômeno Humano. Tradução de Léon Bourdon e José Terra. São Paulo: Herder, 1965. 
AUGUSTIN (Saint). Oeuvres de Saint Augustin. Traduc,ão e notas de M. Mellet e T. Camelot. Paris: Institut d'Études Augustiniennes, 1991. (La Trinité, v. 16, livres VIII- X).

AUGUSTINUS (Sanctus). De trinitate. In: MOUNTAIN, W. J.; GLORIE, F. (ed.). Corpus Chirstianorum Series Latina (CCSL). Turnholti: Typographi Brepols, 1968. v. 50-50A.

AUGUSTINUS (Sanctus). Opera Omnia. Nuova Biblioteca Agostiniana. Rome: Città Nuova, 1965 .

Fontes secundárias:

ARISTÓTELES. Órganon. Tradução de Edson Bini. São Paulo: Edipro, 2005. BOÉCIO. Escritos (Opuscula Sacra). Tradução de Juvenal Savian Filho. São Paulo: Martins Fontes, 2005.

CAMELOT, T.; MELLET, M. Notes complémentaires. In: AUGUSTIN (Saint). Oeuvres de Saint Augustin. Traduc,ão e notas de M. Mellet e T. Camelot. Paris: Institut d'Études Augustiniennes, 1991. (La Trinité, v. 15, livres I-VII).

CHARDIN, T. O fenômeno humano. Tradução de Léon Bourdon e José Terra. São Paulo: Herder, 1965.

FOLCH GOMES, C. A doutrina da trindade eterna: O significado da expressão "três Pessoas". Rio de Janeiro: Lumen Christi, 1979.

HENDRICKX, E. Introduction. In: AUGUSTIN (Saint). Oeuvres de Saint Augustin. Traduc,ão e notas de M. Mellet e T. Camelot. Paris: Institut d'Études Augustiniennes, 1991. (La Trinité, v. 15, livres I-VII). p. 7-76.

HENRY, P. Saint Augustine on personality. New York: Macmillan, 1960.

LLOYD, A. C. On Augustine's concept of a person. In: MARKUS, A. (ed.). Augustine: a collection of critical essays. Garden City: Doubleday, 1972. p. 191-205.

MCPARTLAN, P. Pessoa. In: LACOSTE, J, Y. (org.). Dicionário crítico de teologia. São Paulo: Loyola, 2004.

O' CONNOR, W. R. O. The concept of the person in St. Augustine's De Trinitate. Augustinian Studies, [s. l.], v. 13, p. 133-143, 1982. https://doi.org/10.5840/ augstudies19821312

PAIVA, G. B. V. Transcendentes ou transcendentais? Um ensaio sobre Kant e o erro dos escolásticos. Cadernos de Filosofia Alemã, São Paulo, v. 20, n. 2, p. 179-200, 2015. https://doi.org/10.11606/issn.2318-9800.v20i2p179-200 
ROSA, J. M. S. Da relacional antropologia franciscana. In: BONI, L. A. (org.). João Duns Scotus (1308-2008): homenagem de scotistas lusófonos. Porto Alegre: EDIPUCRS, 2008. p. 281-290. https://doi.org/10.15448/1984-6746.2008.3.4302 VAZ, H. L. Antropologia filosófica II. São Paulo: Loyola, 1992.

\section{Endereço Postal:}

Mariana Paolozzi

Email: marianapaolozzi1@gmail.com

Programa de Pós-Graduação em Filosofia

Universidade Federal de Santa Catarina - UFSC

Campus Universitário Trindade, Caixa Postal 476, Florianópolis - SC, $88.040-970$ 